Article

\title{
Stiffness of Plasma Sprayed Thermal Barrier Coatings
}

\author{
Shiladitya Paul \\ Materials Group, TWI, Cambridge CB21 6AL, UK; shiladitya.paul@twi.co.uk; Tel.: +44-1223-899-000 \\ Academic Editor: Yasutaka Ando \\ Received: 23 March 2017; Accepted: 2 May 2017; Published: 9 May 2017
}

\begin{abstract}
Thermal spray coatings (TSCs) have complex microstructures and they often operate in demanding environments. Plasma sprayed (PS) thermal barrier coating (TBC) is one such ceramic layer that is applied onto metallic components where a low macroscopic stiffness favors stability by limiting the stresses from differential thermal contraction. In this paper, the Young's modulus of TBC top coat, measured using different techniques, such as four-point bending, indentation and impulse excitation is reported, along with a brief description of how the techniques probe different length scales. Zirconia-based TBC top coats were found to have a much lower global stiffness than that of dense zirconia. A typical value for the as-sprayed Young's modulus was $\sim 23 \mathrm{GPa}$, determined by beam bending. Indentation, probing a local area, gave significantly higher values. The difference between the two stiffness values is thought to explain the wide range of TBC top coat Young's modulus values reported in the literature. On exposure to high temperature, due to the sintering process, detached top coats exhibit an increase in stiffness. This increase in stiffness caused by the sintering of fine-scale porosity has significant impact on the strain tolerance of the TBC. The paper discusses the different techniques for measuring the Young's modulus of the TBC top coats and implications of the measured values.
\end{abstract}

Keywords: Young's modulus; thermal barrier coatings; plasma spray; yttria stabilized zirconia (YSZ); four-point bending; indentation; impulse excitation technique; composite beam

\section{Introduction}

\subsection{Background}

Thermal barrier coatings (TBCs) have complex microstructures due to the production process and they operate in demanding environments. Trends towards ever increasing efficiency of aeroengines have dictated the turbine inlet temperatures to rise and hence the demand for thicker TBCs with low thermal conductivity. Typical TBC systems comprise a $\mathrm{ZrO}_{2}$ (stabilised with 6-8 wt \% $\mathrm{Y}_{2} \mathrm{O}_{3}$, also called YSZ) ceramic top coat about 100-500 $\mu \mathrm{m}$ in thickness, deposited either by air plasma spray (APS) or electron beam physical vapour deposition (EB-PVD), over a metallic bond coat that has been vacuum plasma sprayed onto a superalloy substrate. Since these ceramic TBC top coats are applied onto metallic components, low macroscopic stiffness favors stability, by limiting the stresses from differential thermal contraction during production and in service. The main driving force for the spallation of the ceramic TBC top coat is the release of the stored strain energy in the layers comprising the TBC system. The stored energy within the top coat depends linearly on the in-plane Young's modulus, but this parameter is often difficult to define. The difficulty is often related to the techniques available for measuring the Young's modulus. In the following section, an overview is presented of the literature available on the stiffness of plasma sprayed (PS) TBCs, along with a brief description of some of the existing techniques to predict such properties and interpretation of the reported data. 


\subsection{Reported Young's Modulus Values of Plasma Sprayed TBC Top Coats}

\subsubsection{General Remarks}

It is known that the stiffness of plasma sprayed (PS) deposits is lower than their dense counterparts. This is because of the presence of microcracks, pores and weak inter-splat bonding. The presence of such microscopic features also results in differences in the mechanical response under different loading conditions and length scales. While the local stiffness of PS TBCs might be close to that of dense zirconia, the global stiffness is commonly an order of magnitude or so lower [1-6]. Literature values show substantial scatter in the elastic modulus of PS YSZ top coats. Since the mechanical properties of PS deposits depend strongly on the microstructure, especially on the presence of microcracks and pores, the evaluation method employed to measure the elastic properties should always be specified. Values of effective elastic modulus may differ considerably, depending on the evaluation method used.

\subsubsection{Indentation}

Measurements performed by indentation with relatively small indenters at low loads that probe small volumes give values approaching that of dense zirconia [3]. To determine the macroscopic or global stiffness of a material, the equivalent contact radius for an indenter is recommended to be approximately an order of magnitude larger than the characteristic length scale [7]. Thus, for indentation of plasma sprayed TBCs, higher load, probing a large volume, should be used to determine its global response. The stiffness and hardness of detached TBC top coats, obtained using a Vickers indenter, is reported to decrease with increasing indenter load [8]. The stiffness obtained at a load of $1 \mathrm{~N}$ was approximately 1.8 times lower than the stiffness at $0.1 \mathrm{~N}$ [3]. Siebert et al [9] carried out measurements using a Vickers pyramid and reported Young's modulus of as-sprayed YSZ in the range of 94-146 GPa. While indenting with a large diamond sphere (radius $=0.2 \mathrm{~mm}$ ), stiffness values of 10-30 GPa were reported even at low loads $(10 \mathrm{mN})$ [3]. In fact, for the large spherical indenter, the contact area is already approximately $350 \pm 70 \mu \mathrm{m}^{2}$ at a load of $10 \mathrm{mN}$ [3]. However, very little difference was observed between the stiffness values obtained at different loads (300-500 N) by indentation of TBC top coats with a large sphere of radius $\sim 1.5 \mathrm{~mm}$ [10]. Wallace et al. [11] reported values for the Young's modulus in the range of 22-38 GPa for as-sprayed YSZ top coats measured using a spherical indenter. One advantage of using indentation is that it can be performed on very small samples. This was used to reveal the elastic anisotropy in PS coatings [11-14]. Higher Young's modulus was observed in the direction perpendicular to the surface [15]. Duan et al [13] reported the in-plane Young's modulus value of attached YSZ coatings to be $\sim 30 \mathrm{GPa}$, and out of plane value to be $~ 61 \mathrm{GPa}$. This anisotropy in plasma sprayed ceramic coatings is often attributed to the fact that the planar crack-like defects have a preferred orientation and that the relative amount of surface area of cracks and pores are different in different directions [11,14]. The surface area of the pores aligned parallel to the substrate is greater than the area of the cracks [16].

\subsubsection{Beam Bending}

Thompson and Clyne [5] reported the Young's modulus values of as-sprayed PS TBC top coat 8-12 GPa by using cantilever bending. Similar values of stiffness, measured by four-point bending, were also reported by Schwingel et al. [6]. They observed that the failure strains generally ranged $0.2-0.4 \%$, whereas failure stresses ranged 4-60 MPa for thick top coats with a high density of segmentation cracks. They also observed that the coating failure occurred at higher stresses when subjected to compressive loading. Mechanical properties of TBCs were also measured by non-destructive resonance techniques $[17,18]$. The values obtained were not too different from the values reported previously by beam bending techniques. However, the strains were low and hence elastic response was seen. The resonance techniques, including the impulse excitation technique (IET), are considered part of the suit of non-destructive testing (NDT) techniques as the likelihood of damage during testing is limited. 


\subsubsection{Behaviour in Tension and Compression}

Plasma sprayed ceramic deposits have been reported to behave differently in tension and compression [2,3,6,19-22]. This difference in behavior is primarily due to the presence of cracks and pores. In tension, microcracks are expected to open and some inter-splat shear is likely to occur. However, under compressive loading, up to a certain strain, the displacement will largely be accommodated by microcrack closure and by inter-splat shear. At sufficiently high compressive strains, however, the microcracks may become fully closed [3]. To further deform the sample, much higher stresses are required. Inter-splat shear displacement might be expected to operate similarly under compression and tension, but since many inter-splat interfaces will be inclined at some angle to the stress axis, a normal compressive stress may develop across them under compressive loading, which would tend to inhibit this shear [5]. As a result of these two effects, the modulus is expected to increase sharply as the compressive strain rises. Fox and Clyne [23] and Paul [24] estimated the microcrack width and the lateral separation between microcracks and deduced that strains of the order of $1-2 \%$ would be required to fully close the microcracks $[5,21]$. Strains reaching these values would thus result

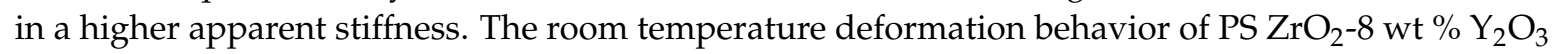
top coat was determined in pure tension and compression by Choi et al. [4]. The TBC top coats did not exhibit any idealized linear stress-strain behavior in both loading and unloading sequences, thus resulting in an appreciable to moderate hysteresis. In order to rationalise the nonlinear elastic behavior, especially for as-sprayed samples, Choi et al. $[2,4,20]$ introduced the concept of an "instantaneous" elastic modulus and attributed the higher "instantaneous" modulus in compression to the porous, microcracked nature of TBCs. Harok and Neufuss [25] attributed this behavior to "internal friction", analogous to the behavior found in rocks, which show inelastic effects under uniaxial compression. It was observed that the hysteresis in the loading and unloading plots is less marked for samples that have been annealed at high temperatures $[1,2,20,26]$.

\subsection{Sintering Effects on Young's Modulus Values of Plasma Sprayed TBCs}

Heat treatment of PS YSZ top coats can result in sintering, particularly in the form of healing of microcracks and improved inter-splat bonding. This will reduce the strain tolerance of the coating and increase the chances of it debonding during service. Siebert et al. [9] observed a rise in Young's modulus from 94 to $144 \mathrm{GPa}$ after annealing for only $2 \mathrm{~h}$ at $1100{ }^{\circ} \mathrm{C}$. Similarly, Eskener and Sandstrom [10] reported an increase from 38 to $60 \mathrm{GPa}$ after heat treatment at $1000{ }^{\circ} \mathrm{C}$ for $1500 \mathrm{~h}$.

Thompson and Clyne [5] and Paul et al. [27] studied the effects of heat-treatment on the microstructural sintering of air-plasma sprayed zirconia in detail. They found that microcrack healing and locking together of overlapping splats via diffusion and grain growth across splat boundaries are the two major sintering mechanisms. Sharp changes in stiffness after short sintering times have also been observed by others [28-30]. While pronounced sintering of zirconia powders is not generally expected at temperatures below $1400{ }^{\circ} \mathrm{C}$, detectable sintering effects have been reported in plasma-sprayed zirconia at temperatures as low as $800^{\circ} \mathrm{C}$ [31].

It is clear that sintering-induced changes in pore architecture, such as microcrack healing and improved inter-splat bonding, can cause shrinkage and stiffening of the top coat. Moreover, sintering can also cause significant increase in the though-thickness thermal conductivity, reducing the thermal protection offered to the substrate [32,33].

\subsection{Scope of the Paper}

Clearly, there is a large body of literature on the mechanical properties of thermal sprayed zirconia and the effect in-service sintering has on these properties. However, the values of the mechanical properties such as coating stiffness, or, more specifically, the Young's modulus, vary by orders of magnitude depending on the technique employed. No single study elucidates the differences with a clear explanation for the observed differences. The only paper on the topic by Tillmann et al. [34] 
reports the Young's modulus of thermal spray coatings measured by bending, nanoindentation and IET. However, they studied WC-Co and fused WC-FeCSiMn coatings prepared by high velocity oxy-fuel (HVOF) and twin wire arc-spray (TWAS), respectively, which are microstructurally very different to plasma sprayed zirconia and, in addition, no study on the behavior after thermal treatment was reported.

This paper aims to address the above knowledge gap by comparing the stiffness of plasma sprayed thermal barrier coatings in as-deposited condition and after heat treatment by using various techniques, such as indentation, impact excitation and beam bending. An attempt is also made to measure the stiffness of the coating while still attached to the substrate. The implication of the technique used on the observed stiffness values is also discussed.

\section{Materials and Methods}

\subsection{Sample Preparation}

Samples were made of yttria-stabilised zirconia (YSZ). Specimens were produced by air plasma spraying (APS) of YSZ powders $\left(4 \mathrm{~mol} \% \mathrm{Y}_{2} \mathrm{O}_{3}\right.$ ) onto mild steel substrates of $1.5 \mathrm{~mm}$ thickness. Details of the spraying conditions can be found elsewhere [32]. Samples for mechanical testing were prepared by debonding the top coats from their substrates by treatment in a $1: 1 \mathrm{HCl}$ bath. The coatings had thicknesses ranging $0.5-1.5 \mathrm{~mm}$. One set of coating was left attached to the substrate for measuring the stiffness of the composite beam. The porosity levels $(\phi)$ in material of this type have been measured previously and are typically around 10-15\% [27]. The thicknesses of the coatings used for the different tests are given in Table 1.

Table 1. The coating thicknesses applied in each test condition.

\begin{tabular}{ccc}
\hline Test & Coating Thickness, $\boldsymbol{t}(\mathbf{m m})$ & Comments \\
\hline $\begin{array}{c}\text { Four-point bending and IET of } \\
\text { stand-alone coatings }\end{array}$ & 0.65 & Detached coatings were used \\
\hline $\begin{array}{c}\text { Four-point bending and IET of } \\
\text { coatings on steel substrate }\end{array}$ & 1.40 & Attached coatings were used \\
\hline Microindentation & 0.30 & The samples were polished before testing \\
\hline Nanoindentation & 0.30 & \\
\hline
\end{tabular}

Heat treatments were performed in order to investigate the effect of sintering on the top coat. Detached top coats were heat treated in air at $1200{ }^{\circ} \mathrm{C}$ and $1400{ }^{\circ} \mathrm{C}$, with a heating rate of $20^{\circ} \mathrm{C} \mathrm{min}-1$. The dwell times at these temperatures were between 1 and $20 \mathrm{~h}$. After heat treatment, the samples were air cooled.

\subsection{Microstructural and Pore Architectural Characterisation}

Microstructural characterization was carried out using a JEOL 6340F FEG-SEM (JEOL, Tokyo, Japan) with EDX detector (JEOL, Peabody, MA, USA). The ceramic top coats needed to have a sputtered layer of $\mathrm{Au}$ to avoid charging during SEM examination. The porosity and pore size distribution was estimated using a MicroMeritics AutoPore IV (Micromeretics Ltd., Norcross, GA, USA). A known mass of the sample was placed in a glass penetrometer, which was evacuated and then back-filled with mercury. The mercury was forced into the specimen by application of external pressure. Details of the procedure used for mercury intrusion porosimetry (MIP) can be found elsewhere [24]. 


\subsection{Measurement of Coating Stiffness}

\subsubsection{General Remarks}

Stiffness was measured using beam bending and indentation methods. Two different techniques were used for each type of measurement. For beam bending it was impulse excitation technique (IET) and four-point bending, and, for indentation, a small Berkovich and relatively large spherical indenters were used (Micro Materials Ltd., Wrexham, UK).

\subsubsection{Indentation}

A Berkovich nanoindenter (load range $0.1-500 \mathrm{mN}$ ) and a $650 \mu \mathrm{m}$ radius $\left(R_{\mathrm{i}}\right) \mathrm{WC}$ spherical microindenter (load range $0.1-20 \mathrm{mN}$ ) were used. A typical experiment consisted of controlled loading and unloading of a diamond indenter against a specimen surface, whilst simultaneously measuring the penetration depth. Analysis was performed according to the Oliver and Pharr method [35]. This assumes that, while loading involves both elastic and plastic deformation of the specimen, recovery of the specimen upon unloading is purely elastic.

From the data collected whilst unloading, a "reduced modulus" $\left(E_{\mathrm{r}}\right)$ can be calculated, which is determined from the compliance of the indenter frame $\left(C_{\mathrm{f}}\right)$ and the initial gradient of the unloading curve (Figure 1), using Equation (1):

$$
\frac{\mathrm{d} l}{\mathrm{~d} F}=\left(\sqrt{\frac{\pi}{A}} \frac{1}{2 E_{\mathrm{r}}}\right)+C_{\mathrm{f}}
$$

where $A$ is the projected area of elastic contact, which is determined from the displacement, $l$, according to the predetermined diamond area function. The specimen's Young's modulus $\left(E_{\mathrm{s}}\right)$ can then be extracted from this according to the Equation (2):

$$
\frac{1}{E_{\mathrm{r}}}=\frac{\left(1-v_{\mathrm{s}}^{2}\right)}{E_{\mathrm{s}}}+\frac{\left(1-v_{\mathrm{i}}^{2}\right)}{E_{\mathrm{i}}}
$$

where $v_{\mathrm{i}}$ and $v_{\mathrm{s}}$ are the respective Poisson ratios for the diamond of the indenter and for the specimen, and $E_{\mathrm{i}}$ is the Young's modulus of diamond.

Values of $v_{\mathrm{i}}=0.07$ and $E_{\mathrm{i}}=1147 \mathrm{GPa}$ were assumed for the diamond indenter [35]. The modulus and Poisson's ratio for the WC spherical indenter were taken as $\sim 773 \mathrm{GPa}$ and 0.24 respectively. Frame compliance, $C_{\mathrm{f}}$, was found to be between 0.48 and $0.50 \mathrm{~nm} / \mathrm{mN}$, and $v_{\mathrm{s}}$ is reported to be $\sim 0.23[36,37]$.

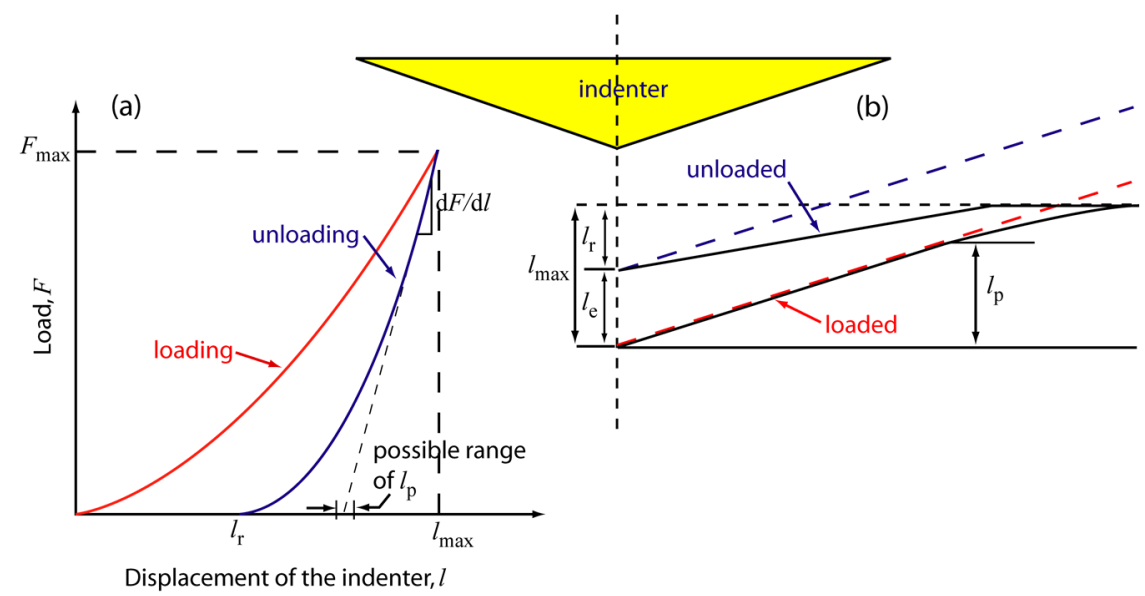

Figure 1. Schematic representation of (a) typical load-displacement curve, and (b) corresponding geometrical parameters for a pyramidal indenter, showing definition of key parameters. The load is in $\mathrm{mN}$ and the displacement is in $\mathrm{nm}$. 
However, before the Young's modulus can be obtained, the elastic area of contact has to be determined. For a Berkovich pyramid, this is given by [35]:

$$
A \sim 24.5 l_{\mathrm{p}}^{2}
$$

and that for a spherical indenter is given by

$$
A=2 \pi R_{\mathrm{i}} l_{\mathrm{p}}\left(1-\frac{l_{\mathrm{p}}}{2}\right)
$$

The contact depth, $l_{\mathrm{p}}$, immediately before unloading can be obtained by [35]

$$
l_{\mathrm{p}}=l_{\max }-\beta\left[\frac{F_{\max }}{(\mathrm{d} F / \mathrm{d} l)}\right]
$$

where $\beta$ is a geometrical constant with values $\sim 0.72$ (for a conical/pyramidal indenter) and $\sim 0.75$ (or a spherical indenter) [35].

\subsubsection{Beam Bending}

Cantilever bending experiments were performed in preliminary work, but four-point bending was ultimately selected because this allowed application of a uniform bending moment to a large area of coating, minimizing the chances of coating damage during the test. However, due to the fragile nature of the detached coatings, it was not possible to determine the Young's modulus in four-point bending with a conventional hydraulic mechanical testing machine. Instead, it was necessary to use a purpose-built four-point rig described elsewhere [24].

The four-point bending rig assembly was placed in the path of a scanning laser extensometer, to measure deflections. The laser extensometer was allowed to run for a few hours before the experiments were performed. This allows measurement of the deflections with a resolution of $\sim 0.5 \mu \mathrm{m}$. Load was applied via a counter-balanced platen, using small pre-weighed masses. A brief period ( 10 min) was allowed for the beam to settle after each addition. Using the deflection $(\delta)$ measured at the centre, the bending modulus was determined by:

$$
E=\frac{F a}{48 I \delta}\left(3 L^{2}-4 a^{2}\right)
$$

where $a$ is the distance between the inner and outer loading points, and $L$ is the distance between the two outer loading points, $F$ is the applied load and $I$ is the second moment of area, which, for a specimen beam with width $b$ and thickness, $h_{\mathrm{b}}$, is given by:

$$
I=\frac{1}{12} b h_{\mathrm{b}}^{3}
$$

The instrument was sufficiently sensitive to allow four-point bend testing of free-standing PS top coats. Known load increments were made and the deflection of the sample was recorded.

IET is a non-destructive technique, which allows determination of elastic moduli from the flexural resonance frequency. The dimensions of the beam were first measured, and then it was weighed and supported at predicted nodal points. A small mechanical impulse was then applied near an anti-node, and the resulting flexural resonance frequency was monitored acoustically. The resonance frequency and damping analyser (RFDA, IMCE, Diepenbeek, Belgium) was then used, applying a fast Fourier transformation to convert the measured signal into frequencies. The fundamental flexural resonance frequency of the beam $\left(f_{\mathrm{r}}\right)$ could then be identified, and the modulus is given by:

$$
E=0.9465\left(\frac{m f_{\mathrm{r}}^{2}}{b}\right)\left(\frac{L^{3}}{h^{3}}\right) C_{1}
$$


where $m$ is the sample mass, $b, L$ and $h$ are the sample dimensions, and $C_{1}$ is a correction factor, which depends on the $L / h$ ratio and on the Poisson ratio. For our specimens, this was found to be $\sim 1$ [38].

This technique is less restrictive in terms of geometry than four-point bending arrangements, and it can be performed very rapidly. Both detached and attached coatings were used. It was observed that the $f_{\mathrm{r}}$ can be determined with a repeatability in the order of $1 \mathrm{~Hz}$. This variation is too small to affect the accuracy of the calculated elastic modulus, which is dominated by the accuracy of the measured sample dimensions, especially by its thickness.

A four-point beam bending technique and IET were used to measure the Young's modulus of the detached coatings before and after heat treatments. These techniques were also used to measure the stiffness of the coating while attached to the substrate. The equations used to calculate the Young's modulus of the coating from the composite beam data are given in Appendix A.

\section{Results}

\subsection{Indentation}

Nanoindentation was performed with a Berkovich diamond. Regions relatively devoid of cracks and surface defects were identified using a microscope and at least 15 indents made in those regions. A loading and unloading rate of $2.6 \mathrm{mN} \mathrm{s}^{-1}$ was used. Typical load-displacement curves are shown in Figure 2. Young's modulus of the top coat was obtained by using the unloading part of the load displacement curve following Oliver and Pharr's method [35] as described earlier (Section 3.2.2). During loading, some 'kinks' were sometimes observed. These were not included in the analysis as they often indicate cracking of the material tested.

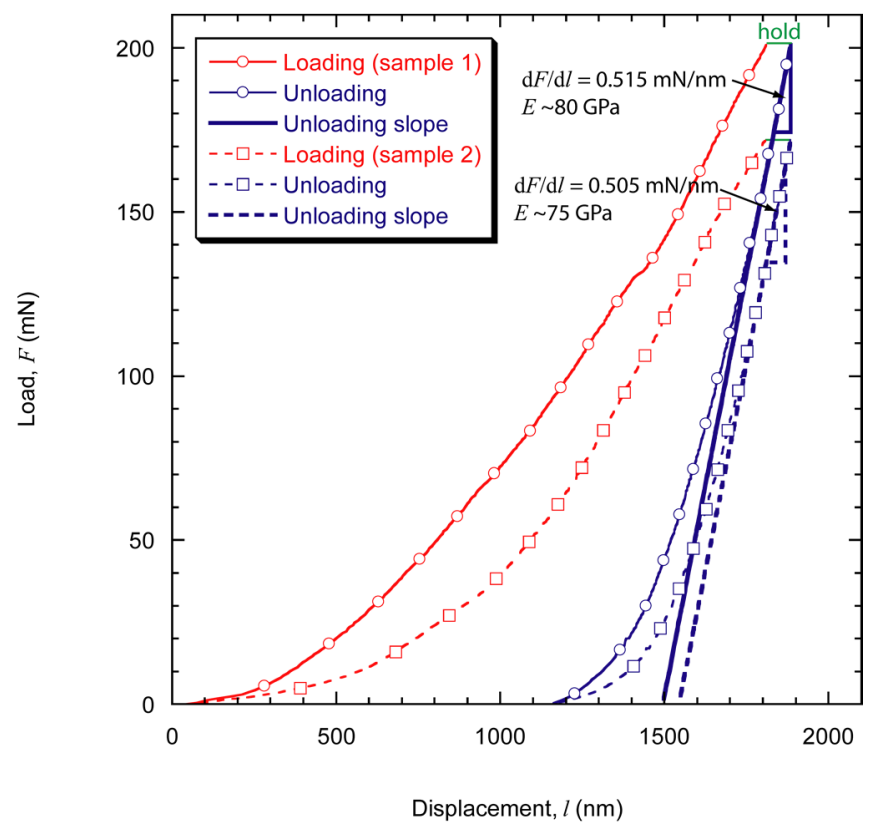

Figure 2. Two examples of load-displacement curves for loading and unloading of an as-sprayed top coat under nanoindentation testing. Fifteen indentation tests were performed, but only two are shown here (with only $5 \%$ of the data points) for clarity.

The Young's modulus for as-sprayed YSZ top coat in the through-thickness direction was found to be about $82 \pm 20 \mathrm{GPa}$. It seems likely that the presence of some fine porosity in the form of cracks or small pores beneath the indenter lowers the value of Young's modulus from its fully dense counterpart, which is $\sim 200-210 \mathrm{GPa}$ [39]. The indents were shallow ( 1.8 $\mu \mathrm{m}$ deep) compared to the thickness of the coating (few hundreds of micrometres), so the substrate effect is assumed to be negligible. Similarly, 
the roughness $\left(R_{\mathrm{a}} \sim 200 \mathrm{~nm}\right.$ ) is also small (10\% of indentation depth), but not negligible compared to the indentation depth. Thus, one would expect some effect on the indentation values, but this effect is unlikely to be significant.

Similar tests were also carried out using a large spherical microindenter. The average Young's modulus for the as-sprayed YSZ in the through-thickness direction, as measured using a $650 \mu \mathrm{m}$ (radius) spherical WC microindenter, was found to be $23 \pm 3 \mathrm{GPa}$ (from 15 indents). This value is almost an order of magnitude lower than that of dense zirconia and a quarter of that obtained from nanoindentation.

\subsection{Beam Bending}

\subsubsection{Attached Coatings}

One set of specimen was tested in the attached state. Two different experiments were carried out using (i) four-point bending and (ii) impulse excitation technique (IET).

Load versus deflection plot for the attached coatings is shown in Figure 3. It is evident that the coating failed at a lower load under tension. The nature of the curve is also different depending on the nature of coating stress state, i.e., tension or compression.

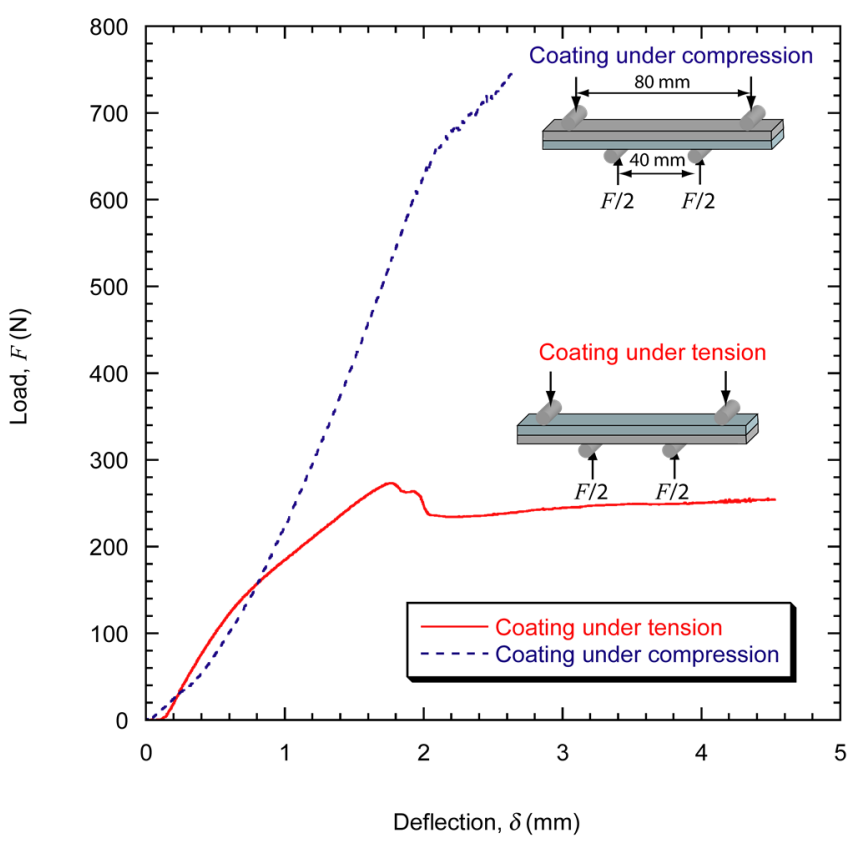

Figure 3. Load versus deflection plot for the attached TBC under tension and compression.

The coating is made of thermal spray ceramic material (zirconia), thus is expected to be weaker in tension than compression. The splat microstructure implies that the opening of the inter-splat and intra-splat pores or cracks is aided by tensile stress. When the coating is under tension, the slope of the load-displacement curve quickly attains a value in line with the Young's modulus of the coating. However, with the increase in applied load, more and more cracks begin to appear in the coating, and the cracks begin to propagate, the slope changes and, ultimately, failure of the coating occurs. The load does not instantly fall to a low value because the steel substrate can still undergo plastic deformation before failure. The plastic deformation of the substrate absorbs the applied energy and thinning of the substrate occurs, ultimately reaching a point where the load cannot be accommodated.

In case of the coating under compression, the initial load is used for partial closing of pores and cracks present in the ceramic TBC top coat. As the load increases, more and more compressive stress is generated in the coating, which means that compaction of the coating occurs and the porosity 
is reduced. The slope of the curve increases with load, which indicates the compaction process. Ultimately, when the stress cannot be accommodated in the coating, failure ensues. As the coating is much stronger in compression, failure of the coating indicates failure of the whole system. Unlike the case with the "coating under tension", when the coating is "under compression", it is load bearing. The yield point of the substrate is exceeded prior to the failure of the coating.

The load-displacement curve when converted to a stress-strain curve of the coating gives a better indication of the behavior of the coating (Figure 4). It is evident that the coating behavior is very similar in tension and compression at very low strains. The slope of the stress-strain curve, indicated in Figure 4, gives the Young's modulus of the coating to be $23 \mathrm{GPa}$ at low strains.

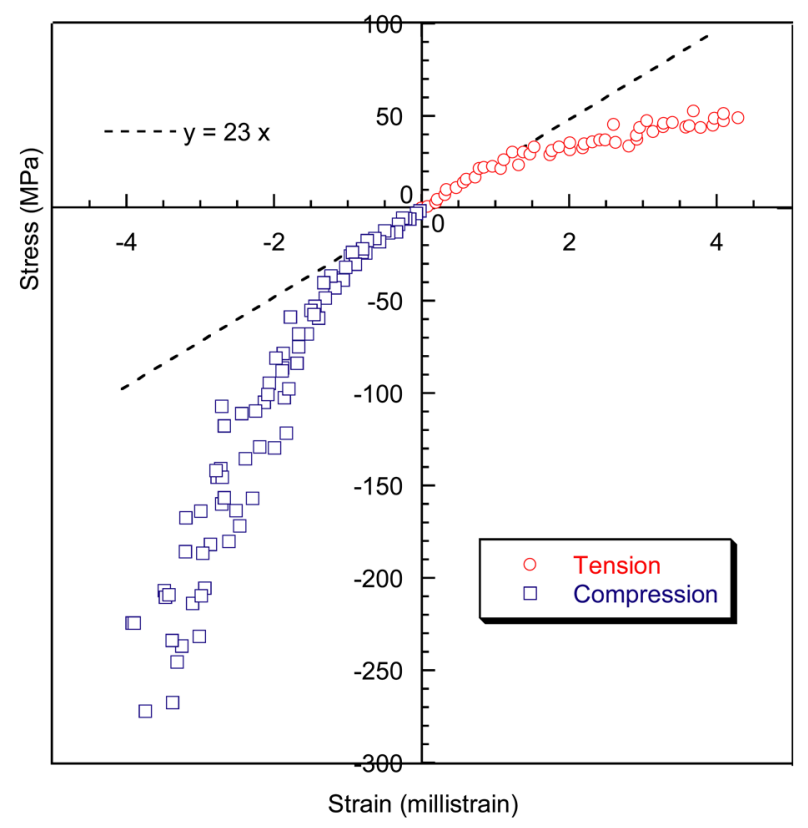

Figure 4. Stress versus strain curve for the TBC top coat. The data was obtained from the attached coating during beam bending.

At high strains $(\varepsilon)$, the stress-strain plot deviates from the line drawn with a slope corresponding to a Young's modulus of $23 \mathrm{GPa}$. The behavior at high strains is dependent on the nature of the stress/strain. Under tensile strain, the coating cracks or further opening of the existing cracks occur and the "apparent" Young's modulus decreases. The use of the term "apparent Young's modulus" is probably more appropriate in cases described above. The concept of Young's modulus is not strictly valid in such situations as the elastic response of the material is not observed. It is more akin to localized failure due to crack opening. Similarly, under high compressive stress, the apparent Young's modulus increases because of closing of the crack-like features. If the process is continued, one may reach the modulus of zirconia. However, such values are difficult to observe when using beam bending experiments. The change is the behavior i.e., from linear to nonlinear occurs by application of one millistrain. Thus, the values reaching the Young's modulus of dense zirconia are unlikely to be obtained by beam bending.

In addition to four-point bending, impulse excitation technique (IET) was also used to measure the fundamental flexural frequency (FFF) of the attached coating. This was found to be $874.7 \mathrm{~Hz}$ (Figure 5). 


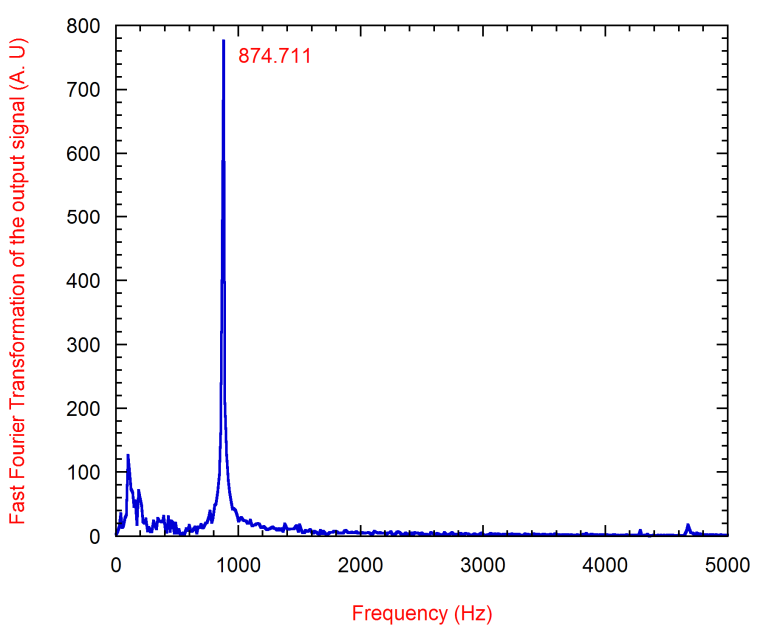

Figure 5. IET output signal as a function of frequency. The peak corresponds to the FFF.

This, when incorporated into Equation (8), gave the apparent modulus of the coated beam to be $58 \mathrm{GPa}$. When this value is incorporated in Equation (A14) (Appendix A), one gets the apparent Young's modulus of the TBC top coat as $22 \mathrm{GPa}$.

\subsubsection{Detached or Free-Standing TBC Top Coats}

To obtain a global in-plane stiffness of TBCs, beam bending experiments were performed on free-standing coatings. During four-point bend testing of as-sprayed free-standing top coats, some hysteresis was observed in the loading-unloading sequence (Figure 6). Due to this behavior, it was difficult to obtain a single-valued Young's modulus $(E)$ of the coating. However, an average value of the gradient from the load-unload sequence was used in Equation (6) to make an estimate of the coating Young's modulus. The elastic modulus of the free standing as-sprayed YSZ top coat was found to be about $23 \pm 4 \mathrm{GPa}$. Young's modulus of the detached coating was calculated to be $22 \pm 3 \mathrm{GPa}$ using the IET. The values obtained by the two techniques are in agreement.

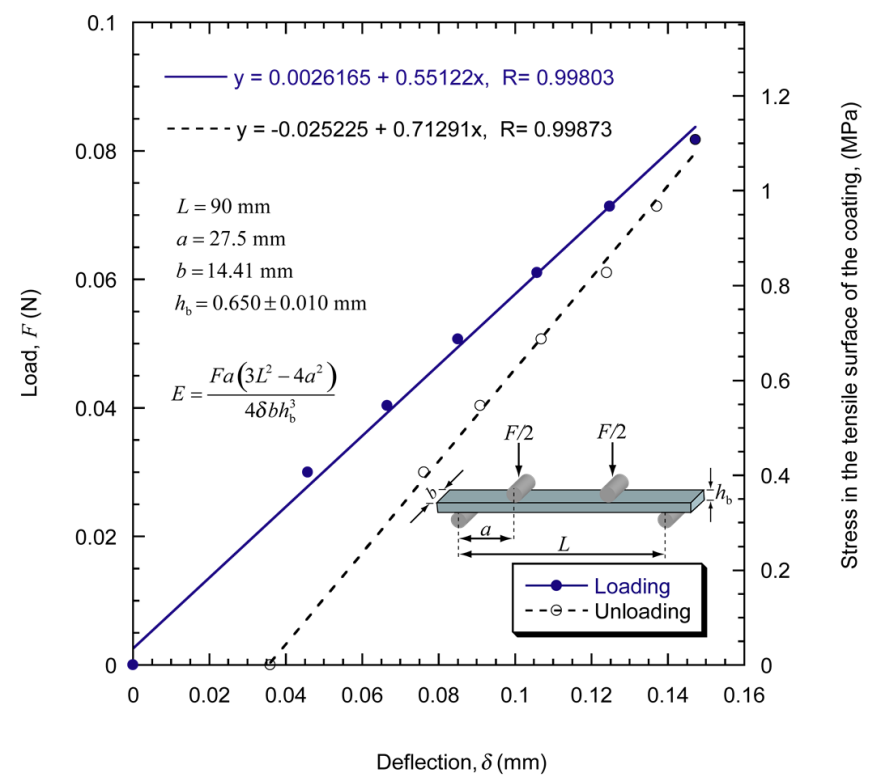

Figure 6. Load-unload plot for a free-standing as-sprayed YSZ (204NS) top coat during four-point bend testing. The maximum surface strain for this particular beam, as measured by strain gauging, was found to be $<\sim 55$ microstrain. 
Although the global fracture stress may not be reached during these tests, the stresses achieved may lead to opening of cracks [6]. Thus, the inelastic effect is attributed to the possible opening of cracks and/or sliding of splats during initial loading, with the cracks then failing to close fully when the load is removed.

\subsection{Effect of Heat Treatment}

\subsubsection{Stiffness of Detached or Free-Standing Coatings}

Heat treatment was only carried out on detached top coats. After heat treatment, the hysteresis observed in the loading-unloading sequence of as-sprayed free-standing coating decreased. Due to this behavior, it was easier to obtain a single-valued elastic modulus of the coating material after various heat treatments. It can be seen in Figure 7 that the effect of heat treatment on the stiffness of PS YSZ is significant. This is particularly true for samples heat treated at $1400{ }^{\circ} \mathrm{C}$, which generated more than a two-fold increase in stiffness after $20 \mathrm{~h}$, as measured by beam bending. There appears to be an initial rapid increase, even for samples heat treated at $1200^{\circ} \mathrm{C}$. This initial rapid increase is followed by further progressive increases.

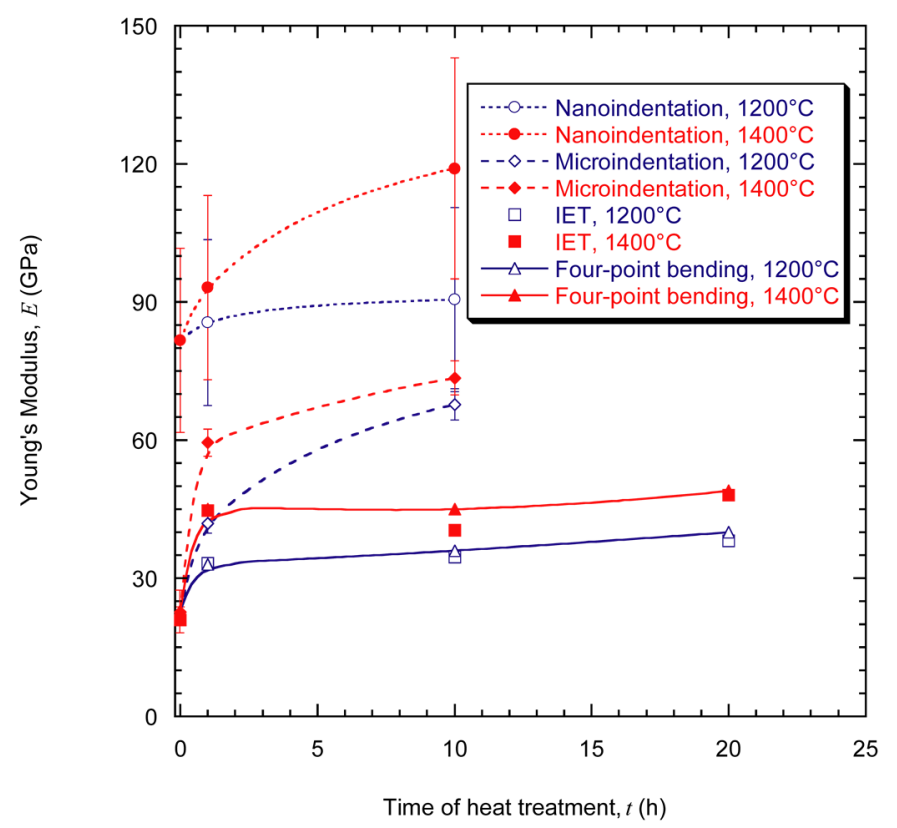

Figure 7. Young's Modulus data of detached YSZ top coats subjected to various prior heat treatments. Error bars represent the standard deviation of at least 15 indents.

The effect of heat treatment on the apparent Young's modulus is clear. However, the starting Young's moduli obtained from different techniques are different. The scatter in the data is also dependent on the technique used. The IET and four-point beam bending method gave similar values, with the local indentation technique giving higher values. The effect of length scale is clear from the data presented in Figure 7.

\subsubsection{Pore Architecture in Detached or Free-Standing Coatings}

Thermal spray coatings are generated by molten droplets impacting the substrate and spreading to form pancake-shaped splats, typically with a splat thickness of 1-3 $\mu \mathrm{m}$ (Figure 8). It can be seen that, in general, there is relatively poor bonding between overlapping splats. Some bridging areas between asperities on the contacting surfaces are inevitably present, but there are often relatively large areas of poor contact that allow the sliding of splats. Some pores are also seen in the micrograph. 


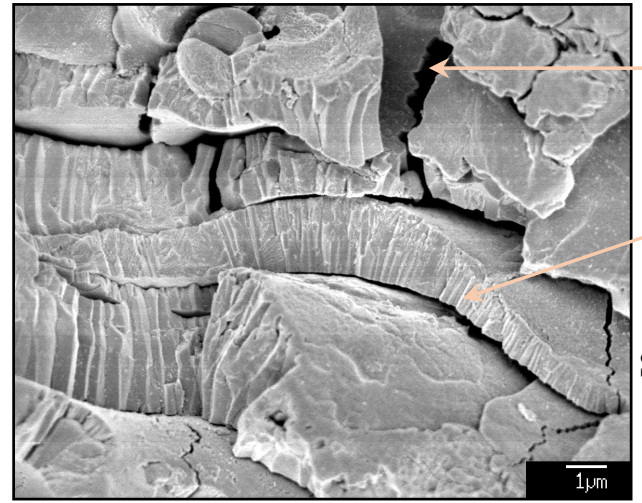

(a)

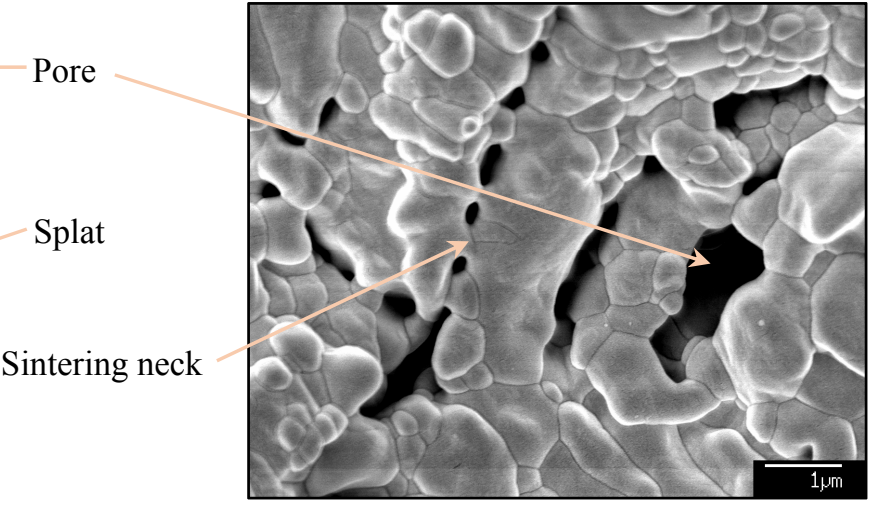

(b)

Figure 8. SEM micrographs of plasma sprayed TBC top coat before (a) and after (b) heat treatment at $1400{ }^{\circ} \mathrm{C}$ for $10 \mathrm{~h}$.

Isothermal heat treatments result in grain boundary grooving (thermal etching), causing grain boundaries to become more clearly visible. Prominent grain boundaries can be seen after $10 \mathrm{~h}$ heat treatment at $1400{ }^{\circ} \mathrm{C}$ (Figure 8). Some grain growth can also be seen in the top coats. Heat treatment causes transport of matter, often bridging interfaces between splats in close physical proximity, as shown in Figure 8. There is also evidence of healing of microcracks. However, large voids remain relatively unaffected, even after $10 \mathrm{~h}$ of heat treatment at $1400{ }^{\circ} \mathrm{C}$. This is also evident from the porosity measurements (Figure 9).

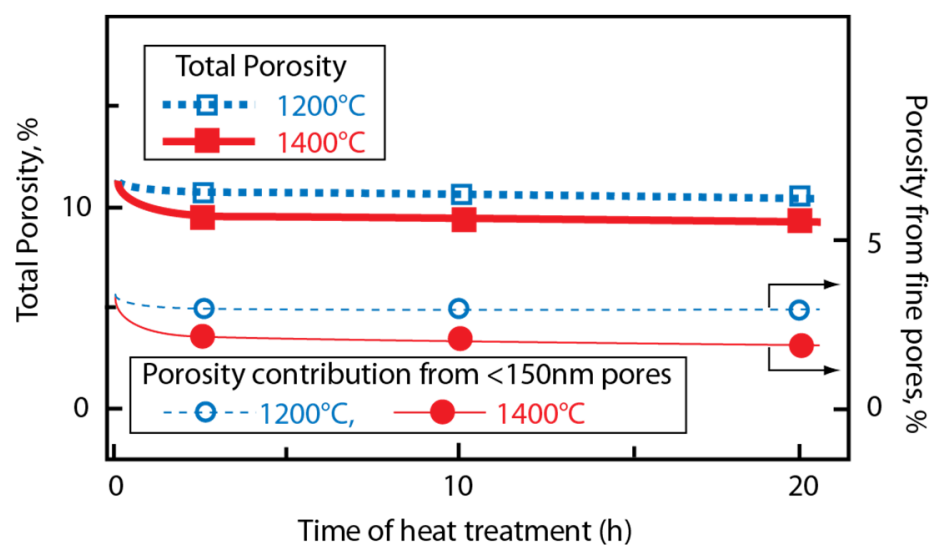

Figure 9. Porosity data, showing the effect of heat treatment on total porosity and fine-scale porosity for detached PS top coats.

The porosity levels of the as-sprayed coatings are similar, with the average lying around $10-12 \%$. It can be seen that the total porosity possibly decreases slightly with heat treatment, and the change is on the order of $0.5-3 \%$. The small change in overall porosity is consistent with the microstructural changes seen in the coatings. It is clear that, during heat treatment, the larger pores remain relatively unaffected, while the small pores sinter. In a network of pores, as in the case of PS TBCs, the complex interplay between different diffusion mechanisms would give rise to complex pore geometries. The sintering of small pores, which contribute little towards change in the overall porosity (Figure 9), might cause changes in the surface-connected porosity by closing the throats to larger pores. Thus, the change in fine-scale porosity and closed porosity would give information about the sintering behavior of top coats with different heat treatment regimes. Most significant changes seem to take place in the sub-150 nm region. These fine pores, which have a large surface to volume ratio, are major contributors 
to the surface area. Reduction in the number of such pores would not alter the overall porosity by much, but would significantly reduce the overall surface area.

\section{Discussion}

\subsection{Local Stiffness}

The average surface roughness of the samples indented was $200 \mathrm{~nm}$ (after polishing). The maximum depth during indentation was $\sim 1.8 \mu \mathrm{m}$ (Figure 10). Systematic underestimation of hardness and stiffness has been reported due to surface roughness effects [40]. For uniformly-spaced pyramidal asperities, a roughness of just $10 \%$ of the indentation depth will result in the modulus being underestimated by $\sim 20 \%$ [3]. This puts restrictions on the use of nanoindentation data for sample with roughness values exceeding $200 \mathrm{~nm}$. For the present work, the roughness of the samples could possibly result in the modulus being reduced to $\sim 160-170 \mathrm{GPa}(20 \%$ reduction in modulus from the dense value). However, the modulus obtained is about half of the above value. This significant reduction is probably due to the presence of flaws in the coating. Surface roughness and sub-surface flaws produce a large scatter. In spite of the scatter, it is clear that nanoindentation gives the local stiffness, and is expected to be much higher than the global value.

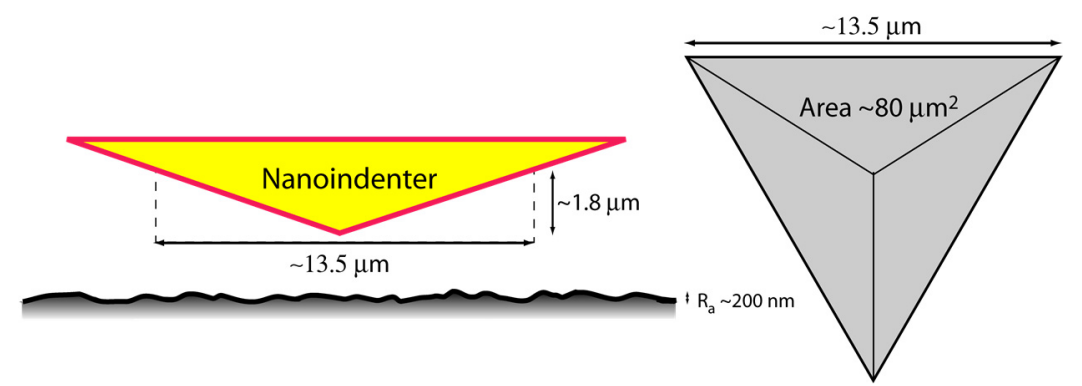

(a)

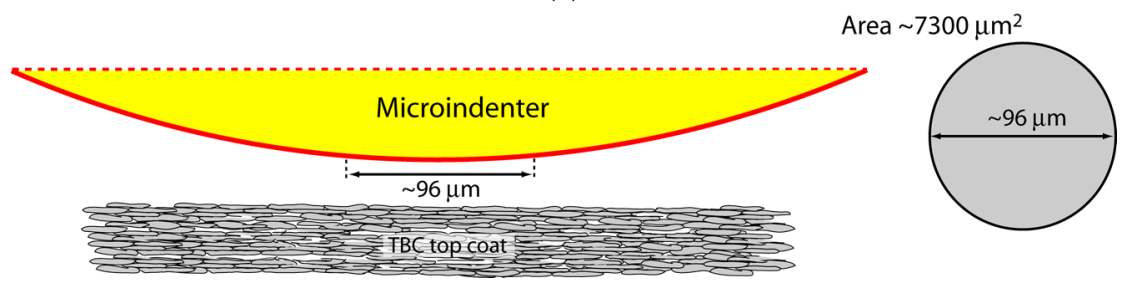

(b)

Figure 10. Schematic showing: (a) nanoindentation and (b) microindentation of a PS TBC top coat.

\subsection{Global Stiffness}

The elastic modulus of the free standing as-sprayed YSZ top coat was found to be about $23 \pm 4 \mathrm{GPa}$. This is in general agreement with data in the literature concerning the global modulus of such coatings $[2,5,19,41]$. As expected, this value is about an order of magnitude lower than that of bulk zirconia. This reduction is attributed to the presence of microstructural defects, particularly the high density of inter-splat voids and intra-splat microcracks. Both of these defect types result in an increase in coating compliance. However, it is worth noting that the in-plane stiffness, as measured in bend testing, is expected to be more dependent on the density of intra-splat microcracks. An extensive array of such cracks, orientated perpendicular to the loading direction, can reduce the stiffness significantly.

The difference between the values obtained by the two indenters has some implication on the choice of technique and length scales. The difference is most likely due to the larger and thus more representative area indented during microindentation (because more defects are covered in the indented area). For $\sim 1.8 \mu \mathrm{m}$ deep indent, a Berkovich pyramid probes an area of $\sim 80 \mu \mathrm{m}^{2}$, while, for similar indentation depth, the spherical microindenter probes an area exceeding $7000 \mu \mathrm{m}^{2}$ (Figure 10). 
The scatter in the modulus for larger indents is also smaller than that of nanoindentation, due to the fact that the local stiffness depends on the proximity of the indent to a flaw.

\subsection{Effect of Service Conditions}

The work performed on the free-standing coating showed that the global Young's modulus of the as-sprayed coating is only about $10 \%$ of that for the dense material. This is due to the high density of defects. It might therefore be expected that healing of such defects will result in a significant increase in Young's modulus [42]. Consequently, stresses generated as a result of a given misfit strain (e.g., as a result of a specified temperature change while attached to the substrate), and thus the interfacial strain energy release rate for delamination, will be raised.

While large globular pores are expected to remain unaffected by the heat treatment, fine scale porosity (intra-splat microcracks and inter-splat voids), which are primarily responsible for the high compliance, tend to heal quickly, even at $1200{ }^{\circ} \mathrm{C}$, as shown schematically in Figure 11 . The healing or the sintering process will lock the microstructure and hinder the sliding of splats as a strain accommodating mechanism, and thus result in sharp increase in stiffness after short heat treatment times. This is in agreement with previous observations for similar coatings $[1,5,29,32]$.

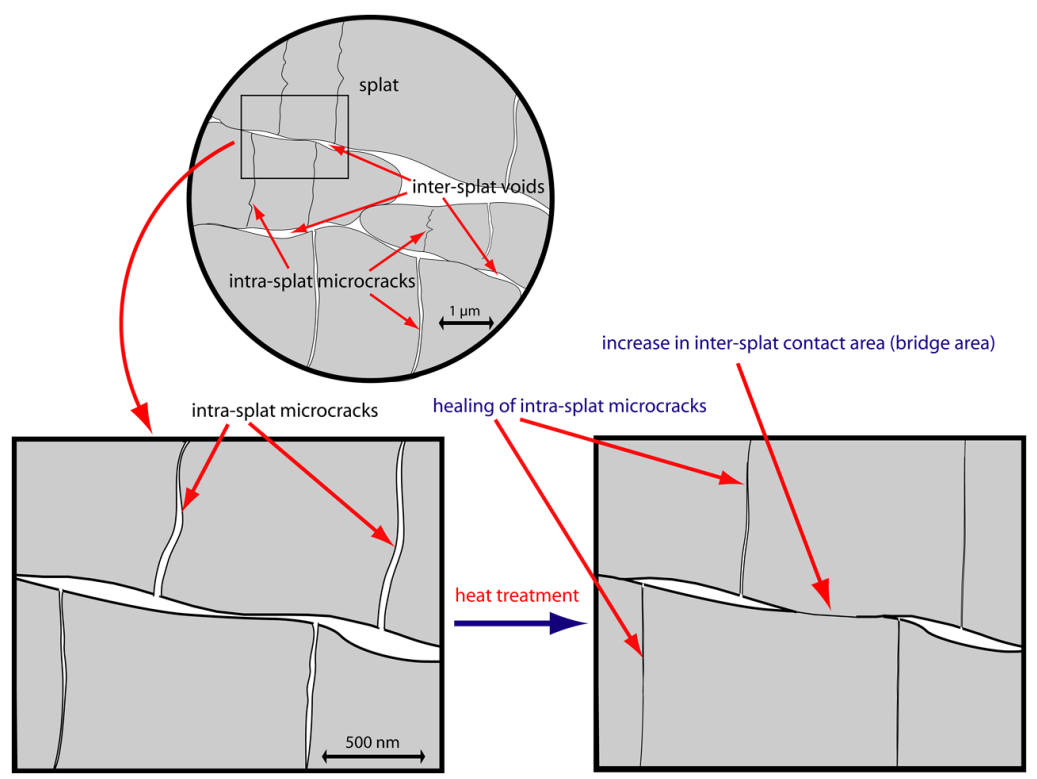

Figure 11. Schematic showing the effect of heat treatment on the pore architecture of PS coatings.

The rate of sintering at a given temperature would depend on the diffusion coefficient, which is dependent on the dominant mechanism of mass transport (e.g., grain or grain boundary). The presence of defects in the structure enhances diffusion. In zirconia containing an aliovalent dopant like yttria, the introduction of yttria results in the formation of oxygen vacancies. The $\mathrm{Y}^{3+}$ ions replace $\mathrm{Zr}^{4+}$ in the cationic sublattice, thereby generating oxygen vacancies to maintain charge neutrality. These oxygen vacancies play an important role in the diffusion process within YSZ. The slowest (rate-controlling) diffusional process in YSZ is suggested to be the transport of cations [43], since the oxygen vacancies have far lower activation energy for diffusion than the solute cations. The diffusion coefficients of $\mathrm{Zr}^{4+}$ and $\mathrm{O}^{2-}$ in $\mathrm{ZrO}_{2}$ are reported to be $10^{-19}$ and $2 \times 10^{-13} \mathrm{~m}^{2} \cdot \mathrm{s}^{-1}$ [44].

From the usually accepted Arrhenius equation, the diffusion coefficient $(D)$, the diffusion pre-exponential factor $\left(D_{0}\right)$ and the activation energy barrier $\Delta E$ are generally extracted using Equation (9):

$$
D=D_{0} \exp \left(\frac{-\Delta E}{R T}\right)
$$


The values found in literature are presented in Table 2 below. The values can be taken as guide for the diffusion for the system studied in the current paper.

Table 2. Diffusivity data for $\mathrm{Zr}^{4+}$ in $3 \mathrm{~mol} \% \mathrm{Y}_{2} \mathrm{O}_{3}-\mathrm{ZrO}_{2}$ system at $1400{ }^{\circ} \mathrm{C}$ [45].

\begin{tabular}{ccc}
\hline Diffusion Type & Pre-Exponential Factor, $D_{\mathbf{0}}\left(\mathbf{m}^{\mathbf{2}} \cdot \mathbf{s}^{\mathbf{- 1}}\right)$ & Activation Energy, $\Delta E\left(\mathbf{k J} \cdot \mathbf{m o l}^{-\mathbf{1}}\right)$ \\
\hline Lattice & $5 \times 10^{-4}$ & 515 \\
Grain Boundary & $1 \times 10^{-3}$ & 370 \\
\hline
\end{tabular}

Although diffusivities are very sensitive to impurity levels, and there is very little data available in the literature [45-48], it is worthwhile to compare the diffusion distances for typical sintering times with the size of the defects present in PS YSZ. For a polycrystalline material, the overall diffusion coefficient can be assumed to be the sum of contributions from the lattice and grain boundary. Thus, the overall diffusion coefficient is given by [24]:

$$
D_{\text {tot }}=D_{\text {lat }}+\frac{2 h_{\mathrm{gb}}}{d_{\text {grain }}} D_{\mathrm{gb}}
$$

where the subscripts tot, lat and gb refer to the overall, lattice and grain boundary diffusion coefficients. The grain boundary thickness and grain size are referred to as $h_{\mathrm{gb}}$ and $d_{\text {grain, }}$ respectively. Plasma sprayed zirconia have columnar grains with the column size in the order of 1-3 $\mu \mathrm{m}$ and width in the order of a few hundred nanometres. A grain size of $1 \mu \mathrm{m}$ and grain boundary thickness of $1 \mathrm{~nm}$ was assumed in the following calculations. Incorporation of these values into Equation (10) and using the simple expression $x=\sqrt{D t}$ the diffusion distance $(x)$ was calculated (Figure 12).

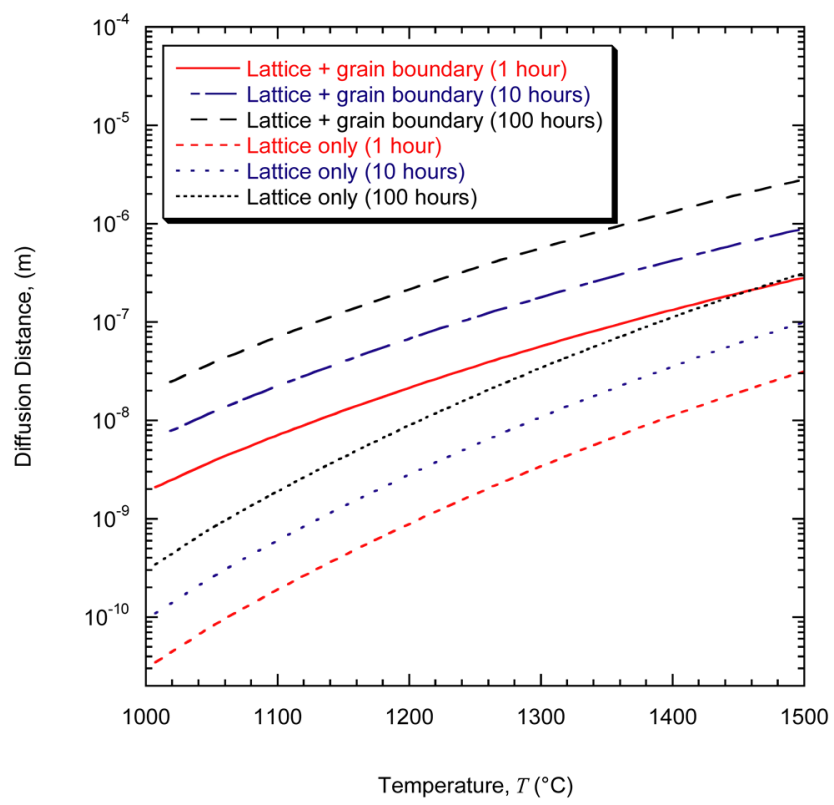

Figure 12. Calculated diffusion distances for $\mathrm{Zr}^{4+}$ ions in tetragonal zirconia, obtained using data in Table 2.

Figure 12 shows the diffusion distances as a function of temperature at different times. It should be noted that the diffusion data used to calculate these distances apply to $3 \mathrm{~mol} \% \mathrm{Y}_{2} \mathrm{O}_{3}-\mathrm{ZrO}_{2}$ system, which is slightly different from the system studied here (4 mol \% $\mathrm{Y}_{2} \mathrm{O}_{3}-\mathrm{ZrO}_{2}$ system). As such, these comparisons are of largely qualitative nature, but it is useful to note that diffusion distances are often of the order of the defect size. The plot suggests that, for typical heating time and temperatures used, 
only fine scale pores are likely to be sintered. For healing of large globular pores $(\geq 1 \mu \mathrm{m})$, longer heat treatment times $(>100 \mathrm{~h})$ at high temperatures $\left(\geq 1400^{\circ} \mathrm{C}\right)$ would be required.

It is also worth noting the difference between diffusion distances for lattice and grain boundary diffusion. The total diffusivity is dominated, in these calculations, by grain boundary diffusion. This is largely due to the small grain size (and thus a high fraction of grain boundary volume) resulting from rapid quenching of molten splats during coating deposition.

The intra-splat microcrack healing would increase the stiffness of the splats, whereas the inter-splat voids would lock the structure together, making it stiffer (giving higher local and global moduli). Both of these stiffening mechanisms operate in TBCs. Once the finest flaws with highest surface to volume ratio are healed, the rate of sintering drops and so does the rate of stiffening.

In spite of the large scatter in the modulus, as seen particularly for nanoindentation, clear increase in the values can be observed after heat treatment, which is in line with the sintering characteristics expected for the top coat. The scatter in the data is considerably lower in the case of microindentation with a WC sphere. The modulus obtained from indentation was consistently higher than that obtained from bending tests. A number of factors could be responsible for this effect.

It has been reported earlier that higher compressive stress, as experienced during indentation, may lead to partial closure of microcracks, and the elastic response of the top coat with partially closed microcracks would lead to a higher stiffness [3]. Note must also be made of the fact that, while bending of free-standing coating gave the in-plane stiffness (averaging the tensile-compressive responses), indentation (in the present work) gave a modulus only in the through-thickness direction. Although the as-sprayed modulus obtained from microindentation agrees reasonably well with the values obtained from bending, after heat treatment, the rate of increase of modulus measured by microindentation is greater than that for bending. This is possibly due to anisotropy in the sintering behaviour of the top coat, which shrinks more in the through-thickness direction than the in-plane direction $[24,27,30,32]$.

\section{Conclusions}

It has been confirmed that the stiffness of PS zirconia top coats is much lower than that of dense zirconia. A typical value for the as-sprayed Young's modulus was $\sim 23 \mathrm{GPa}$, determined by four-point bend testing. Local measurements by nanoindentation revealed significantly higher stiffness values $(82 \pm 20 \mathrm{GPa})$. The difference between the global and local stiffness is likely to explain the wide range of top coat stiffness values reported in the literature.

On exposure to high temperature, due to the sintering process, detached top coats exhibit changes in pore architecture (particularly in the sub-150 nm size range), with healing of intra-splat microcracks and enhanced inter-splat bonding. These changes lead to significant increases in both in-plane and through-thickness stiffness.

The measurement method of the Young's modulus of thermally sprayed coatings has an impact on the values obtained. The techniques reported in this paper include bending tests, indentation and impact excitation technique. During the bending tests, performed on a beam (either with or without the substrate), sliding of the splats can occur due to the laminar structure of the plasma sprayed zirconia, influencing the measurement value. When using the nanoindentation, only the elastic behavior of some splats can be determined because of a minimal measuring volume, while microindentation with a large indenter can give a more global picture. IET can be used to give the global Young's modulus of the coating both when attached to the substrate and detached from it.

It is worth noting that the present work on the sintering behavior was carried out on detached top coats, and it is known that sintering effects are retarded by the tensile strains present when coatings are attached to substrates. Thus, in situ monitoring of stiffness and thermal conductivity of different top coat compositions in service is a logical next step. 
Acknowledgments: The author highly appreciates the discussions with, and guidance from, Bill Clyne (Cambridge). The author also acknowledges the support from Igor Golosnoy (Southampton) and Vasant Kumar (Cambridge).

Conflicts of Interest: The author declares no conflict of interest.

\section{Nomenclature}

\section{Roman Symbols}

\begin{tabular}{|c|c|}
\hline$a, \mathrm{~m}$ & Characteristic length in beam bending \\
\hline$A, \mathrm{~m}^{2}$ & Area \\
\hline$b, \mathrm{~m}$ & Beam width \\
\hline C & Constant \\
\hline$C_{1}$ & Correction factor for IET \\
\hline$C_{\mathrm{f}}, \mathrm{nm} \mathrm{mN}^{-1}$ & Frame compliance \\
\hline$d_{\text {grain }}, \mathrm{m}$ & Grain diameter \\
\hline$D, \mathrm{~m}$ & Diffusion coefficient \\
\hline$E, \mathrm{~N} \mathrm{~m}^{-2}(\mathrm{~Pa})$ & Young's modulus \\
\hline$E_{\mathrm{c}}, \mathrm{N} \mathrm{m}^{-2}(\mathrm{~Pa})$ & Young's modulus of the coating \\
\hline$E_{\mathrm{i}}, \mathrm{N} \mathrm{m}^{-2}(\mathrm{~Pa})$ & Young's modulus of the indenter \\
\hline$E_{\mathrm{s}}, \mathrm{N} \mathrm{m}^{-2}(\mathrm{~Pa})$ & Young's modulus of the substrate or specimen \\
\hline$\Delta E, \mathrm{~J} \mathrm{~mol}^{-1}$ & Activation energy \\
\hline$f_{\mathrm{r}}, \mathrm{Hz}$ & Resonance frequency \\
\hline$F, \mathrm{~N}$ & Force or Load \\
\hline$h, \mathrm{~m}$ & Height \\
\hline$h_{\mathrm{b}}, \mathrm{m}$ & Height of beam in 4-pt bending \\
\hline$h_{\mathrm{gb}}, \mathrm{m}$ & Grain boundary thickness \\
\hline$I, \mathrm{~m}^{4}$ & Second moment of area \\
\hline$L, \mathrm{~m}$ & Length or distance \\
\hline$l, \mathrm{~m}$ & Indentation depth \\
\hline$l_{\mathrm{e}}, \mathrm{m}$ & Depth of elastic recovery during indentation \\
\hline$l_{\max }, \mathrm{m}$ & Maximum depth attained by the indenter \\
\hline$l_{\mathrm{p}}, \mathrm{m}$ & Contact depth during indentation \\
\hline$l_{\mathrm{r}}, \mathrm{m}$ & Residual depth during indentation \\
\hline$m, \mathrm{~kg}$ & Mass \\
\hline$R_{\mathrm{i}}, \mathrm{m}$ & Radius of the indenter \\
\hline$t, \mathrm{~m}$ & Thickness \\
\hline$t_{\mathrm{c}}, \mathrm{m}$ & Thickness of the coating \\
\hline$t_{\mathrm{s}}, \mathrm{m}$ & Thickness of the substrate \\
\hline$y_{\mathrm{nn}}, \mathrm{m}$ & Position of the neutral axis \\
\hline
\end{tabular}

\section{Greek Symbols}

$\begin{array}{ll}\beta & \text { Geometrical constant (for an indenter) } \\ \delta, \mathrm{m} & \text { Displacement/deflection } \\ \varepsilon & \text { Strain } \\ \phi & \text { Porosity } \\ v & \text { Poisson's ratio } \\ v_{i} & \text { Poisson's ratio of the indenter } \\ v_{s} & \text { Poisson's ratio of the sample }\end{array}$

\section{Acronyms}

APS

BET

EB-PVD

FFF
Atmospheric (Air) Plasma Spray

Brunauer-Emmett-Teller ( $\mathrm{N}_{2}$ adsorption isotherm)

Electron Beam Physical Vapour Deposition

Fundamental Flexural Frequency 


$\begin{array}{ll}\text { HVOF } & \text { High Velocity Oxy-Fuel } \\ \text { IET } & \text { Impulse Excitation Technique } \\ \text { MIP } & \text { Mercury Intrusion Porosimetry } \\ \text { NDT } & \text { Non-Destructive Testing } \\ \text { PS } & \text { Plasma Spray } \\ \text { RFDA } & \text { Resonance Frequency and Damping Analyser } \\ \text { SEM } & \text { Scanning Electron Microscopy } \\ \text { TWAS } & \text { Twin Wire Arc Apray } \\ \text { TBC } & \text { Thermal Barrier Coating } \\ \text { YSZ } & \text { Yttria Stabilised Zirconia }\end{array}$

\section{Appendix A}

The apparent modulus of a composite beam can be calculated by considering the equivalent transformed sections. The coating with thickness " $t_{\mathrm{c}}$ ", Young's modulus " $E_{\mathrm{c}}$ " on a substrate of thickness " $t_{\mathrm{s}}$ " and Young's modulus " $Y_{\mathrm{s}}$ " will give a transformed section of $b \times\left(E_{\mathrm{c}} / E_{\mathrm{s}}\right)$, where " $b$ " is the width of the non-transformed section. A schematic explanation is given in Figure A1.

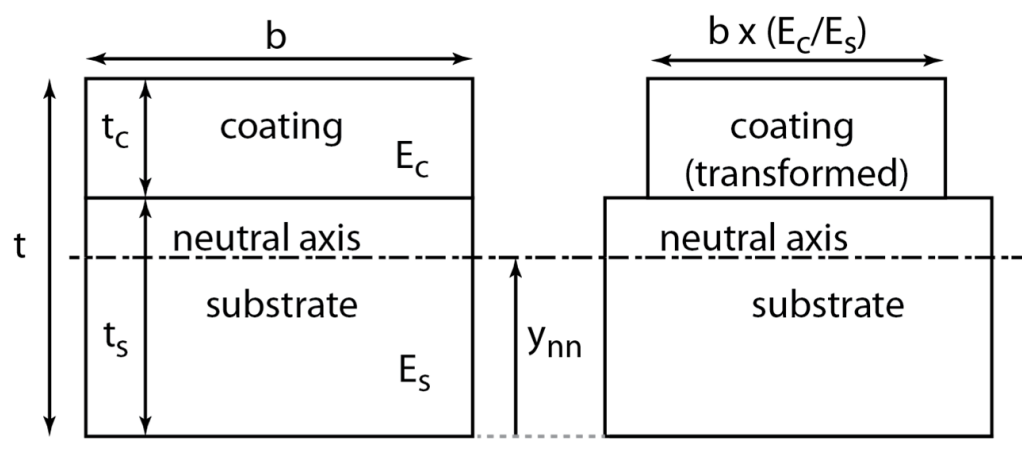

(a)

(b)

Figure A1. Schematic showing the composite beam along with the various notations used in the derivation (a), and the geometry of the transformed section $(\mathbf{b})$.

When bending a cross-section, which is not symmetrical about the centroid, the neutral axis will no longer be in the central line or along the geometrical centre. However, there must exist a line along the cross-section, where the length does not change. The later can be found from the requirement that the following integral must be zero:

$$
\int_{0}^{t}\left(y-y_{n n}\right) \mathrm{d} A=0
$$

where $A$ is the area of the section and $t$ is the thickness of the system or the combined thickness of the substrate and coating, and $y_{\mathrm{nn}}$ is the position of the neutral axis. Substituting the width of the part in question in the above equation using the transformed section, we get:

$$
\int_{0}^{t_{s}}\left(y-y_{n n}\right) b \mathrm{~d} y+\int_{t_{s}}^{t}\left(y-y_{n n}\right) \frac{E_{c}}{E_{s}} b \mathrm{~d} y=0
$$

Since $b \neq 0$, we can re-write the above equation as:

$$
\begin{gathered}
y_{n n}\left\{t_{s}+\frac{E_{c}}{E_{s}}\left(t-t_{s}\right)\right\}=\frac{t_{s}^{2}}{2}+\frac{E_{c}}{E_{s}} \frac{\left(t^{2}-t_{s}^{2}\right)}{2} \\
y_{n n}=\frac{1}{2}\left\{\frac{E_{s} t_{s}^{2}+E_{c}\left(t^{2}-t_{s}^{2}\right)}{E_{s} t_{s}+E_{c} t_{c}}\right\}
\end{gathered}
$$


In addition to the neutral axis, one needs to know the second moment of area to calculate the Young's modulus of the composite beam. The second moment of area is given by:

$$
I=\int_{0}^{t}\left(y-y_{n n}\right)^{2} \mathrm{~d} A
$$

This equation stems from the fact that the overall action of the bending stresses in the cross-section must be equal to the applied bending moment. Thus, the above integral can be expressed as a sum of two integrals over the regions of different width:

$$
\begin{gathered}
\frac{I}{b}=\int_{0}^{t}\left(y-y_{n n}\right)^{2} \mathrm{~d} y \\
\frac{I}{b}=\int_{0}^{y_{n n}}\left(y-y_{n n}\right)^{2} d y+\int_{y_{n n}}^{t_{s}}\left(y-y_{n n}\right)^{2} d y+\int_{t_{s}}^{t} \frac{E_{c}}{E_{s}}\left(y-y_{n n}\right)^{2} d y
\end{gathered}
$$

Solving the above integrals, we get:

$$
\begin{gathered}
\frac{3 I}{b}=y_{n n}^{3}+\left(t_{s}-y_{n n}\right)^{3}+\frac{E_{c}}{E_{s}}\left\{\left(t-y_{n n}\right)^{3}-\left(t_{s}-y_{n n}\right)^{3}\right\} \\
\frac{3 I}{b}=y_{n n}^{3}+\left(1-\frac{E_{c}}{E_{s}}\right)\left(t_{s}-y_{n n}\right)^{3}+\frac{E_{c}}{E_{s}}\left(t-y_{n n}\right)^{3} \\
I=\frac{b}{3}\left[y_{n n}^{3}+\left(1-\frac{E_{c}}{E_{s}}\right)\left(t_{s}-y_{n n}\right)^{3}+\frac{E_{c}}{E_{s}}\left(t-y_{n n}\right)^{3}\right]
\end{gathered}
$$

The apparent modulus of the coated beam can be obtained from the following equations:

$$
E_{a p p} I_{a p p}=E_{S} I
$$

The second moment of area is given by

$$
I_{a p p}=\frac{b h^{3}}{12}
$$

Substituting Equations (A10) and (A12) into Equation (A11), we get

$$
\begin{gathered}
E_{\text {app }}=\frac{E_{s}\left\{\frac{b}{3}\left[y_{n n}^{3}+\left(1-\frac{E_{c}}{E_{s}}\right)\left(t_{s}-y_{n n}\right)^{3}+\frac{E_{c}}{E_{s}}\left(t-y_{n n}\right)^{3}\right]\right\}}{\frac{b h^{3}}{12}} \\
E_{\text {app }}=\frac{4 E_{s}\left[y_{n n}^{3}+\left(1-\frac{E_{c}}{E_{s}}\right)\left(t_{s}-y_{n n}\right)^{3}+\frac{E_{c}}{E_{s}}\left(t-y_{n n}\right)^{3}\right]}{h^{3}}
\end{gathered}
$$

The above Equation (A14) can be used to calculate the apparent Young's modulus of the composite beam or if the apparent modulus is known, the coating modulus can be estimated.

\section{References}

1. Choi, S.R.; Zhu, D.M.; Miller, R.A. Effect of Sintering on Mechanical Properties of Plasma-Sprayed Zirconia-Based Thermal Barrier Coatings. J. Am. Ceram. Soc. 2005, 88, 2859-2867. [CrossRef]

2. Choi, S.R.; Zhu, D.M.; Miller, R.A. Mechanical Properties/database of Plasma-Sprayed ZrO2-8 wt $\% \mathrm{Y}_{2} \mathrm{O}_{3}$ Thermal Barrier Coatings. Int. J. Appl. Ceram. Technol. 2004, 1, 330-342. [CrossRef]

3. Malzbender, J.; Steinbrech, R.W. Determination of the Stress-Dependent Stiffness of Plasma-Sprayed Thermal Barrier Coatings Using Depth-Sensitive Indentation. J. Mater. Res. 2003, 18, 1975-1984. [CrossRef] 
4. Choi, S.R.; Zhu, D.M.; Miller, R.A. Deformation and Strength Behaviour of Plasma Sprayed $\mathrm{ZrO}_{2}-8$ wt $\% \mathrm{Y}_{2} \mathrm{O}_{3}$ Thermal Barrier Coatings in Biaxial Flexure and Trans-Thickness Tension. Ceram. Eng. Sci. Proc. 2000, 21, 653-661.

5. Thompson, J.A.; Clyne, T.W. The Effect of Heat Treatment on the Stiffness of Zirconia Top Coats in Plasma-Sprayed TBCs. Acta. Mater. 2001, 49, 1565-1575. [CrossRef]

6. Schwingel, D.; Taylor, R.; Haubold, T.; Wirgen, J.; Gaulco, C. Mechanical and Thermophysical Properties of Thick PYSZ Thermal Barrier Coatings: Correlation with Microstructure and Spraying Parameters. Surf. Coat. Technol. 1998, 108-109, 99-106. [CrossRef]

7. Nakamura, T.; Qian, G.; Berndt, C.C. Effects of Pores on Mechanical Properties of Plasma-Sprayed Ceramic Coatings. J. Am. Ceram. Soc. 2000, 83, 578-584. [CrossRef]

8. Basu, D.; Funke, C.; Steinbrech, R.W. Effect of Heat Treatment on Elastic Properties of Separated Thermal Barrier Coatings. J. Mater. Res. 1999, 14, 4643-4650. [CrossRef]

9. Siebert, B.; Funke, C.; Vassen, R.; Stover, D. Changes in Porosity and Young's Modulus due to Sintering of Plasma Sprayed Thermal Barrier Coatings. J. Mater. Process. Technol. 1999, 93, 217-223. [CrossRef]

10. Eskner, M.; Sandstrom, R. Measurement of the Elastic Modulus of a Plasma-Sprayed Thermal Barrier Coating using Spherical Indentation. Surf. Coat. Technol. 2004, 177-178, 165-171. [CrossRef]

11. Wallace, J.S.; Ilavsky, J. Elastic Modulus Measurements in Plasma Sprayed Deposits. J. Therm. Spray. Technol. 1998, 7, 521-526. [CrossRef]

12. Leigh, S.H.; Lin, C.K.; Berndt, C.C. Elastic Response of Thermal Spray Deposits under Indentation Tests. J. Am. Ceram. Soc. 1997, 80, 2093-2099. [CrossRef]

13. Duan, K.; Steinbrech, R.W. Influence of Sample Deformation and Porosity on Mechanical Properties by Instrumented Microindentation Technique. J. Eur. Ceram. Soc. 1998, 18, 87-93.

14. Guo, S.; Kagawa, Y. Young's Moduli of Zirconia Top-Coat and Thermally Grown Oxide in a Plasma-Sprayed Thermal Barrier Coating System. Scripta Mater. 2004, 50, 1401-1406. [CrossRef]

15. Li, G.R.; Lv, B.W.; Yang, G.J.; Zhang, W.X.; Li, C.X.; Li, C.J. Relationship Between Lamellar Structure and Elastic Modulus of Thermally Sprayed Thermal Barrier Coatings with Intra-splat Cracks. J. Therm. Spray Technol. 2015, 24, 1355-1367. [CrossRef]

16. Kulkarni, A.; Wang, Z.; Nakamura, T.; Sampath, S.; Goland, A.; Herman, H.; Allen, J.; Ilavsky, J.; Long, G.; Frahm, J.; et al. Comprehensive Microstructural Characterization and Predictive Property Modeling of Plasma-Sprayed Zirconia Coatings. Acta. Mater. 2003, 51, 2457-2475. [CrossRef]

17. Waki, H.; Takizawa, K.; Kato, M.; Takahashi, S. Accuracy of Young's Modulus of Thermal Barrier Coating Layer Determined by Bending Resonance of a Multilayered Specimen. J. Therm. Spray Technol. 2016, 25, 684-693. [CrossRef]

18. Wei, Q.; Zhu, J.; Chen, W. Anisotropic Mechanical Properties of Plasma-Sprayed Thermal Barrier Coatings at High Temperature Determined by Ultrasonic Method. J. Therm. Spray Technol. 2016, 25, 605-612. [CrossRef]

19. Wakui, T.; Malzbender, J.; Steinbrech, R.W. Strain Dependent Stiffness of Plasma Sprayed Thermal Barrier Coatings. Surf. Coat. Technol. 2006, 200, 4995-5002. [CrossRef]

20. Choi, S.R.; Zhu, D.M.; Miller, R.A. Deformation and Tensile Cyclic Fatigue of Plasma-Sprayed $\mathrm{ZrO}_{2}-8 \mathrm{wt} \%$ $\mathrm{Y}_{2} \mathrm{O}_{3}$ Thermal barrier Coatings. Ceram. Eng. Sci. Proc. 2001, 22, 427-434.

21. Kroupa, F.; Dubsky, J. Pressure Dependence of Young's Moduli of Thermal Sprayed Materials. Scripta Mater. 1999, 40, 1249-1254. [CrossRef]

22. Malzbender, J. The Use of Theories to Determine Mechanical and Thermal Stresses in Monolithic, Coated and Multilayered Elastic Modulus or Gradient in Elastic Materials with Stress-Dependent Modulus Exemplified for Thermal Barrier Coatings. Surf. Coat. Technol. 2004, 186, 416-422. [CrossRef]

23. Fox, A.C.; Clyne, T.W. Oxygen Transport through the Zirconia Top Coat in Thermal Barrier Coating Systems. In Thermal Spray: Meeting the Challenges of the 21st Century, Proceedings of the 15th International Thermal Spray Conference, Nice, France, 25-29 May 1998; ASM International: Materials Park, OH, USA, 1998.

24. Paul, S. Pore Architecture in Ceramic Thermal Barrier Coatings. Ph.D. Thesis, University of Cambridge, Cambridge, UK, September 2007.

25. Harok, V.; Neufuss, K. Elastic and Inelastic Effects in Compression in Plasma-Sprayed Ceramic Coatings. J. Therm. Spray. Technol. 2001, 10, 126-132. [CrossRef]

26. Zhu, D.M.; Miller, R.A. Thermal Conductivity and Elastic Modulus Evolution of Thermal Barrier Coatings under High Heat Flux Conditions. J. Therm. Spray. Technol. 2000, 9, 175-180. [CrossRef] 
27. Paul, S.; Cipitria, A.; Golosnoy, I.O.; Xie, L.; Dorfman, M.R.; Clyne, T.W. Effects of Impurity Content on the Sintering Characteristics of Plasma-Sprayed Zirconia. J. Therm. Spray. Technol. 2007, 16, 798-803. [CrossRef]

28. Zhu, J.; Ma, K. Microstructural and mechanical properties of thermal barrier coating at $1400{ }^{\circ} \mathrm{C}$ treatment. Theor. Appl. Mech. Lett. 2014, 4, 021008. [CrossRef]

29. Eaton, H.E.; Novak, R.C. Sintering Studies of Plasma Sprayed Zirconia. Surf. Coat. Technol. 1987, 32, $227-236$. [CrossRef]

30. Paul, S.; Cipitria, A.; Tsipas, S.A.; Clyne, T.W. Sintering characteristics of plasma sprayed zirconia coatings containing different stabilisers. Surf. Coat. Technol. 2009, 203, 1069-1074. [CrossRef]

31. Wesling, K.F.; Socie, D.F.; Beardsley, B. Fatigue of Thick Thermal Barrier Coatings. J. Am. Ceram. Soc. 1994, 77, 1863-1868. [CrossRef]

32. Paul, S. Assessing Coating Reliability through Pore Architecture Evaluation. J. Therm. Spray Technol. 2010, 19, 779-786. [CrossRef]

33. Curry, N.; Janikowski, W.; Pala, Z.; Vilémová, M.; Markocsan, N. Impact of Impurity Content on the Sintering Resistance and Phase Stability of Dysprosia- and Yttria-Stabilized Zirconia Thermal Barrier Coatings. J. Therm. Spray Technol. 2014, 23, 160-169. [CrossRef]

34. Tillmann, W.; Selvadurai, U.; Luo, W. Measurement of the Young's Modulus of Thermal Spray Coatings by Means of Several Methods. J. Therm. Spray Technol. 2013, 22, 290-298. [CrossRef]

35. Oliver, W.C.; Pharr, G.M. An Improved Technique for Determining Hardness and Elastic Modulus Using Load and Displacement Sensing Indentation Experiments. J. Mater. Res. 1992, 7, 1564-1583. [CrossRef]

36. Lugovy, M.; Slyunyayev, V.; Teixeira, V. Residual Stress Relaxation Processes in Thermal Barrier Coatings under Tension at High Temperature. Surf. Coat. Technol. 2004, 184, 331-337. [CrossRef]

37. Khor, K.A.; Gu, Y.W. Effects of Residual Stress on the Performance of Plasma Sprayed Functionally Graded $\mathrm{ZrO}_{2} / \mathrm{NiCoCrAlY}$. Mat. Sci. Eng. A Struct. 2000, 277, 64-76. [CrossRef]

38. Roebben, G.; Bollen, B.; Brebels, A.; Van Humbeeck, J.; Van Der Biest, O. Impulse Excitation Apparatus to Measure Resonant Frequencies, Elastic Moduli, and Internal Friction at Room and High Temperature. Rev. Sci. Instrum. 1997, 68, 4511-4515. [CrossRef]

39. Green, D.J. An Introduction to the Mechanical Properties of Ceramics (Cambridge Solid State Science Series), 1st ed.; Clarke, D.R., Suresh, S., Ward, I.M., Eds.; Cambridge University Press: Cambridge, UK, 1998.

40. Bobji, M.S.; Biswas, S.K. Deconvolution of Hardness from Data obtained from Nanoindentation of Rough Surfaces. J. Mater. Res. 1999, 14, 2259-2268. [CrossRef]

41. Dwivedi, G.; Nakamura, T.; Sampath, S. Determination of Thermal Spray Coating Property with Curvature Measurements. J. Therm. Spray Tech. 2013, 22, 1337-1347. [CrossRef]

42. Paul, S. Thermal Barrier Coatings. Encyclopedia of Aerospace Engineering; Wiley: Somerset, NJ, USA, 2010.

43. Solomon, H.; Chaumont, J.; Dolin, C.; Monty, C. Zr, Y and O Self Diffusion in $\mathrm{Zr}_{(1-x)} \mathrm{Y}_{x} \mathrm{O}_{2-x / 2}$. In Point Defects and Related Properties of Ceramics; Ceramic Transactions Volume 24; Manson, T.O., Routbourt, J.L., Eds.; American Ceramic Society: Westerville, OH, USA, 1991; p. 175.

44. Anthony, A.M. Sintering and Related Phenomena. In Structure of Point Defects in Ionic Materials; Springer: New York, NY, USA, 1973.

45. Swaroop, S.; Kilo, M.; Argirusis, C.; Borchardt, G.; Chokshi, A.H. Lattice and Grain Boundary Diffusion of Cations in 3YTZ Analyzed using SIMS. Acta Mater. 2005, 53, 4975-4985.

46. Chien, F.R.; Heuer, A.H. Lattice Diffusion Kinetics in $\mathrm{Y}_{2} \mathrm{O}_{3}$-Stabilized Cubic $\mathrm{ZrO}_{2}$ Single Crystals: A Dislocation Loop Annealing Study. Philos. Mag. A 1996, 73, 681-697. [CrossRef]

47. Jimenez-Melendo, M.; Dominguez-Rodriguez, A.; Gomez-Garcia, D.; Bravo-Leon, A.; Martinez-Fernandez, J. Cation Lattice Diffusion in Yttria-Stabilized Zirconia deduced from Deformation Studies. Mater. Sci. Forum. 1997, 239-241, 61-64. [CrossRef]

48. Lakki, A.; Herzog, R.; Weller, M.; Schubert, H.; Reetz, C.; Gorke, O.; Kilo, M.; Borchardt, G. Mechanical Loss, Creep, Diffusion and Ionic Conductivity of $\mathrm{ZrO}_{2}-8 \mathrm{~mol} \% \mathrm{Y}_{2} \mathrm{O}_{3}$ Polycrystals. J. Eur. Ceram. Soc. 2000, 20, 285-296. [CrossRef]

(C) 2017 by the author and TWI. Licensee MDPI, Basel, Switzerland. This article is an open access article distributed under the terms and conditions of the Creative Commons Attribution (CC BY) license (http:/ / creativecommons.org/licenses/by/4.0/). 